\title{
LIPODYSTROPHIC MUSCULAR HYPERTROPHY
}

\author{
BY \\ B. SENIOR* \\ From the Transvaal Memorial Hospital for Children and the University of the Witwatersrand Medical School, \\ Johannesburg
}

(RECEIVED FOR PUBLICATION DECEMBER 29, 1960)

A bizarre disorder was recently encountered in a female child. There was severe lipodystrophy affecting the entire body, generalized muscular hypertrophy, large hands and feet, a markedly protuberant abdomen, hepatomegaly with biochemical and histological evidence of liver dysfunction, a large clitoris, enlarged cystic ovaries and a low fasting blood sugar concentration. This entity is not unique; patients with identical or similar features have previously been described under a variety of titles including the beguiling one of 'leprechaunism' (Ziegler, 1928; Hall, Sunderman and Gittings, 1936; Hansen and McQuarrie, 1940; Lawrence, 1946; Corner, 1952; Murray, 1952; Donohue and Uchida, 1954; Tizard, 1954; Berardinelli, 1954; Fontan, Verger, Couteau and Pery, 1956; Schwartz, Schafer and Renold, 1960; Seip, 1959) (see Table).

It is intended to detail the clinical and other findings in this unusual case and to suggest that the syndrome results from excessive secretion of a specific pituitary hormone.

\section{Case Report}

The patient, A.J., was first seen at the age of 2 years and 10 months. Pregnancy had been uneventful, delivery normal and the birth weight was $6 \mathrm{lb} .12 \mathrm{oz}$. Her appearance at birth was described as 'peculiar' in that she was thin and bony, lacked subcutaneous fat and had a wrinkled face. She gained weight 'but never filled out'. At the age of 6 months enlargement of the clitoris was noticed. At about the same time diarrhoea first appeared, the stools being green, loose and offensive and containing mucus but not blood. Protuberance of the abdomen had been apparent from a very early age and at about 1 year enlargement of the feet was noticed. She sat at 9 months, crawled at 1 year and walked at 18 months. Her speech was limited to a few words. The father was 32 and the mother 20 years old and they were not related. The patient was born of the second pregnancy, the first resulting in a stillborn child of normal appearance. There was a normal female sibling of 18 months.

* Present address: Massachusetts General Hospital, Boston, U.S.A.
On physical examination (Figs. 1-3) the length was $95 \mathrm{~cm}$. (90\%), span $94 \mathrm{~cm}$., and weight $15 \mathrm{~kg}$. (75\%). Subcutaneous fat was lacking over the entire body. There was marked generalized hypertrophy of muscles, especially in the scapular region and extremities and muscle power was extremely good. There was a light brown pigmentation of the skin, particularly over the exposed areas and a fine growth of hair on the face, trunk and limbs; scalp hair was abundant, curly and reddish brown. The head was of normal shape with a circumference of $47.5 \mathrm{~cm}$. A paucity of facial fat gave her an older appearance and made the nose and ears seem unduly prominent. There were 18 teeth, pointed and widely spaced. The thyroid gland was not palpable. A grade 1 parasternal blowing systolic murmur was present and the blood pressure was 80/50 $\mathrm{mm}$. Hg. The abdomen was markedly protuberant and the umbilicus everted. A smooth liver edge was palpated $5 \mathrm{~cm}$. below the right mid-costal margin. The enlarged clitoris was almost $2 \mathrm{~cm}$. long. There was no pubic hair and the vaginal introitus was normal. The superficial veins of the extremities were very prominent, probably as a result of the lack of subcutaneous fat. The reflexes were normal.

The urine was normal chemically and microscopically and chromatography revealed no increase of amino acids. Examination of the blood showed: $\mathrm{Hb} 11 \mathrm{~g}$.


11,500 per c.mm. (neutrophils $22 \%$, lymphocytes $78 \%$, reticulocytes $4 \%$, platelets present in normal numbers); prothrombin index $100 \%$; modified Ide test negative; blood urea $20 \mathrm{mg}$. per $100 \mathrm{ml}$.; serum chloride $98 \mathrm{mEq}$ per litre; serum sodium $135 \mathrm{mEq}$ per litre; serum inorganic phosphorus $5.8 \mathrm{mg}$. per $100 \mathrm{ml}$; serum calcium $8.4 \mathrm{mg}$. per $100 \mathrm{ml}$; alkaline phosphatase 7.6 K.A. units; serum proteins $4.8 \mathrm{~g}$. per $100 \mathrm{ml}$. (albumin 2.02, $\alpha_{1}$ globulin 0.36, $\alpha_{2}$ globulin 0.81, $\beta$ globulin 0.65 , and $\gamma$ globulin $0.76 \mathrm{~g}$. per $100 \mathrm{ml}$.).

The results of a battery of empirical liver function tests were: thymol turbidity $15 \cdot 5$ units; thymol flocculation +++ ; colloidal red ++ ; cephalin cholesterol flocculation + , and zinc sulphate turbidity $13 \cdot 2$ units.

The blood lipogram (average of two estimations) showed: $\alpha_{1}$ and $\alpha_{2}$ cholesterol $19 \% ; \beta$ cholesterol $81 \%$; total lipid $760 \mathrm{mg}$. per $100 \mathrm{ml}$; phospholipids $240 \mathrm{mg}$. per $100 \mathrm{ml}$.; total cholesterol $148 \mathrm{mg}$. per $100 \mathrm{ml}$.; free cholesterol $52 \mathrm{mg}$. per $100 \mathrm{ml}$.; cholesterol esters $96 \mathrm{mg}$. per $100 \mathrm{ml}$.; percentage esters to total $65 \%$; cholesterol 

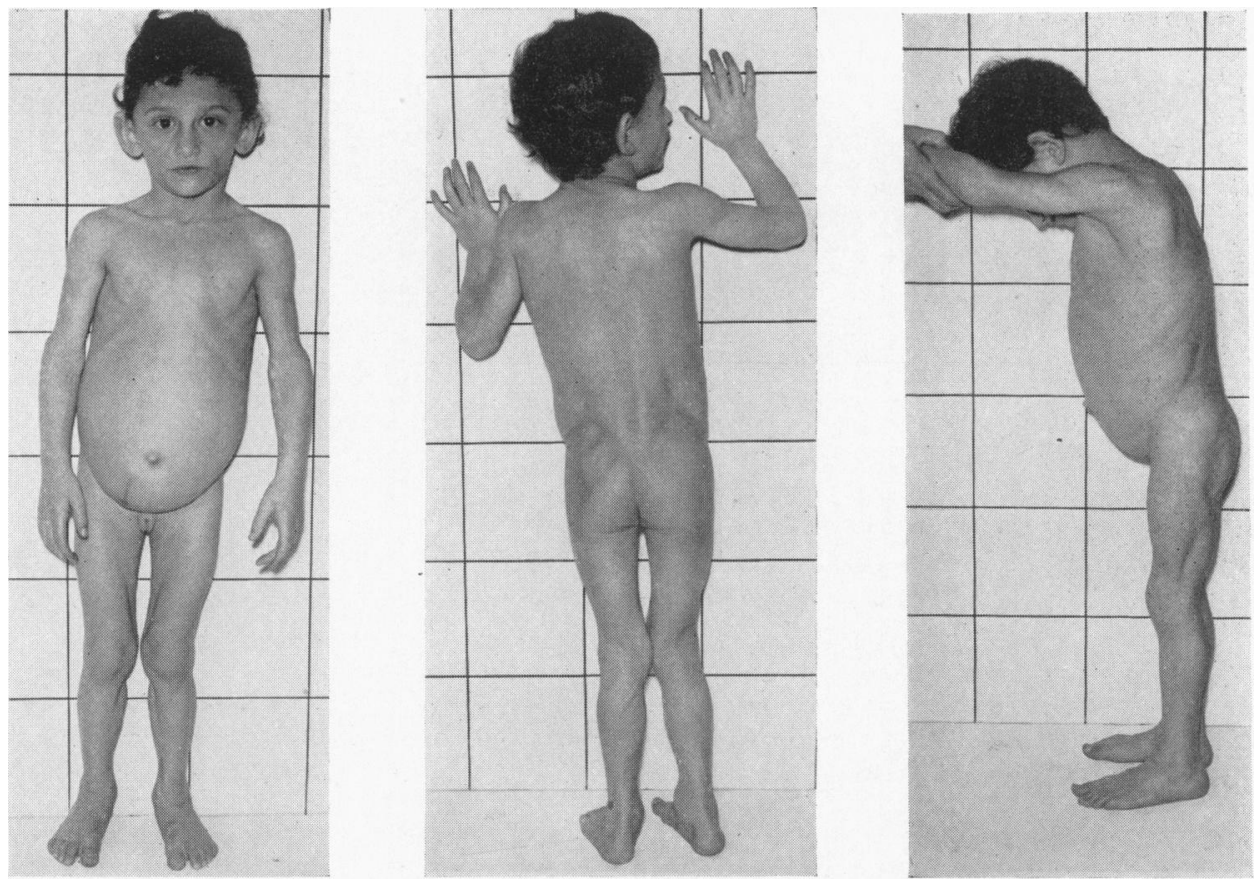

Figs. 1-3.-Lipodystrophy, muscular hypertrophy, protuberance of the abdomen and enlargement of the hands and feet are shown.

phospholipid ratio 0.62 ; total fatty acids $547 \mathrm{mg}$. per $100 \mathrm{ml}$.; neutral fats $312 \mathrm{mg}$. per $100 \mathrm{ml}$.

Repeated estimations of the fasting blood sugar concentration ranged from 36 to $56 \mathrm{mg}$. per $100 \mathrm{ml}$. Following the ingestion of $50 \mathrm{~g}$. glucose the blood sugar concentration rose from a fasting value of $44 \mathrm{mg}$. per $100 \mathrm{ml}$. to $94,112,104,88$ and $80 \mathrm{mg}$. per $100 \mathrm{ml}$. in $30,60,90,120$ and 150 minutes respectively. The blood sugar response to a subcutaneous injection of $1: 1,000$ adrenaline $(0.01 \mathrm{ml}$. per $\mathrm{kg}$.), was a rise from a fasting level of $36 \mathrm{mg}$. per $100 \mathrm{ml}$. to $66,76,83$ and $79 \mathrm{mg}$. per $100 \mathrm{ml}$. at 15, 30, 45 and 60 minutes respectively. An injection of glucagon ( $20 \mu \mathrm{g}$. per $\mathrm{kg}$.) caused a rise in the blood sugar concentration from $58 \mathrm{mg}$. per $100 \mathrm{ml}$. to $104,141,66$ and $58 \mathrm{mg}$. per $100 \mathrm{ml}$. at 15, 30, 60 and 90 minutes.

Repeated stool examinations revealed adequate amounts of trypsin and the absence of fat globules, starch granules. muscle fibres, parasites or bacterial pathogens. A four-day fat balance showed an absorption of $96 \%$ of ingested fat.

The cerebrospinal fluid was normal. The serum protein-bound iodine concentration was $5.5 \mu \mathrm{g}$. \%. The urinary neutral 17 -ketosteroids were $0.63 \mathrm{mg}$. per 24 hours and the 17-hydroxycorticosteroids $2.3 \mathrm{mg}$. per 24 hours. The urinary gonadotrophin excretion was less than 6 mouse units per 24 hours.

Vaginal smears showed a moderate number of intermediate squamous cells, some showing an oestrogenic effect in advance of that expected for the age of the child.
Radiographs of the heart, lungs, skull, vertebrae, pelvis and limbs were normal. The radiological bone age of approximately 3 years corresponded to the chronological age. A barium meal presented normal features. A pneumo-encephalogram was normal.

The electrocardiogram was normal. The electroencephalogram showed random theta and irregular slow wave activity dominating all leads. A minimal amount of random alpha activity was superimposed over the central and post-central areas. This was regarded as an abnormal record but with no asymmetry and no focal or episodic activity.

The mental age on the Vineland Social Maturity Scale was about 16 months, giving a quotient of around $50 \%$.

At diagnostic laparotomy the absence of mesenteric fat was striking. The liver was found to be enlarged and smooth. Histological section revealed small foci of necrosis with infiltration of round cells and a heavy infiltration of round cells in some of the portal tracts. There were also foci of syncitial clumping of nuclei and generalized mild fatty infiltration and marked deposition of glycogen (Figs. 4 and 5).

Sections of abdominal muscle showed slight hypertrophy. A lymph node contained no glycogen. The skin showed a moderate increase of melanin and the cells were chromatin positive.

The ovaries were large and contained many immature follicles and in addition occasional follicular cysts without evidence of luteinization. 


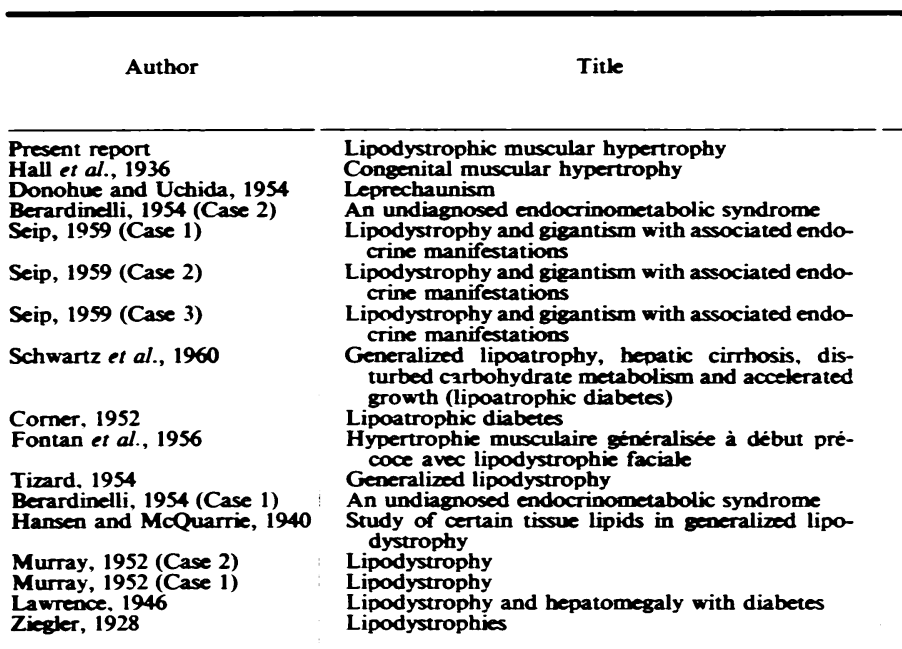

Apparent
Age of Onset

Birth

Birth

Birth

Birth

Birth

Birth

Birth

Birth

10 mths

14 mths

20 mths

? 21 yrs

3 yrs

8 yrs

25 yrs

26 yrs

27 yrs
Age When Seen

by Author

2 yrs 10 mths Birth
Birth

2 yrs 2 mths

6 yrs

1 yr

$11 \mathrm{mths}$

$14 \mathrm{yrs}$

11 yrs

2 yrs 71 mths

$6 \mathrm{yrs}$

47 yrs
yrs

52 yrs

26 yrs
ग

Height

$\overrightarrow{\overline{\vec{n}}}$

$90^{\circ}:$ 을

$90 \% \frac{\bar{C}}{\bar{c}}$

$90 \% \frac{\mathrm{\sigma}}{\mathrm{\sigma}}$

$90 \%$

M

$\mathbf{M}$

$\overrightarrow{0}$

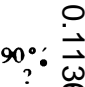

$90 \%$ \%

$90 \div$

o

.

$\infty$

N

- Standard used was growth chart devised by Stuart and Stevenson (1959).

\section{Discussion}

A number of cases identical to or closely resembling the one described have been previously reported but space does not permit their detailed appraisal. The main features appear in the Table and are further discussed below.
Lipodystrophy. In most patients there was an almost total absence of body fat and in our case absence of both mesenteric and perinephric fat was observed at laparotomy. In the less severely affected patients a specific pattern of loss of fat was seen affecting first the face and then progressively

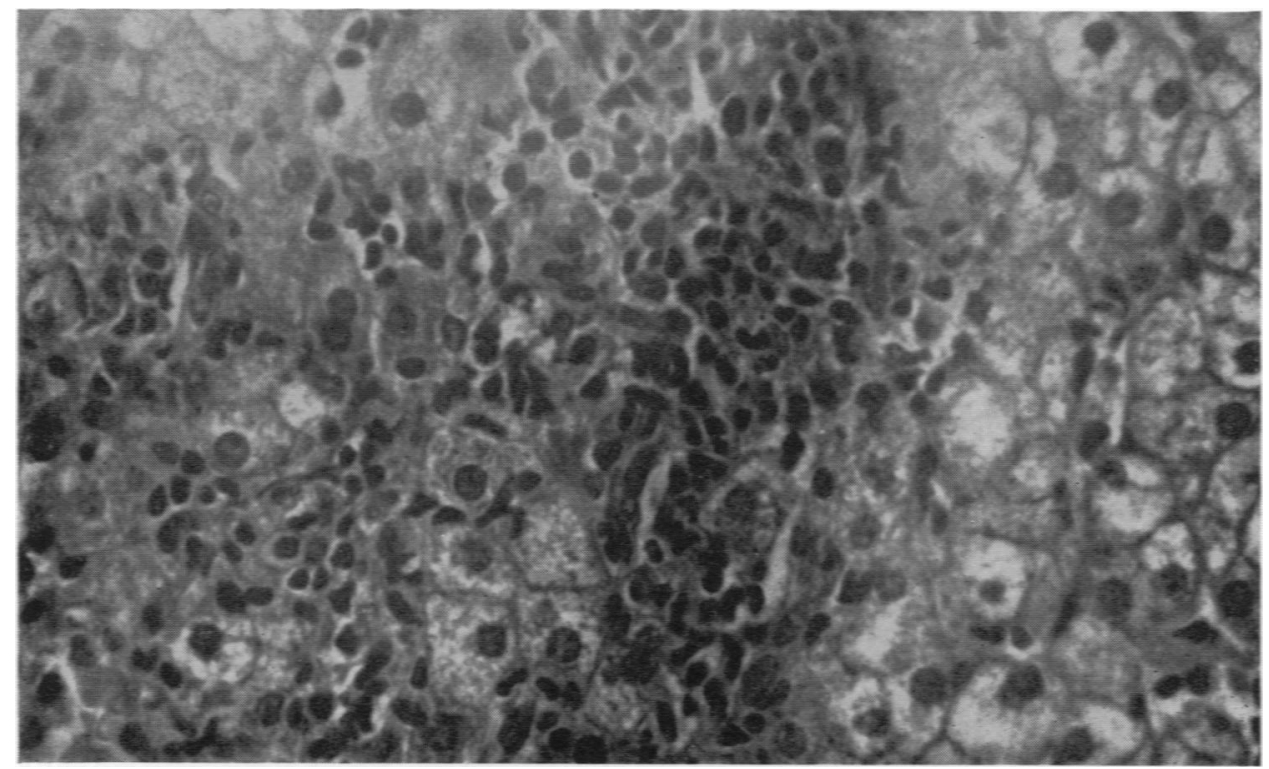

Fig. 4.-Photomicrograph showing section of liver with liver cells (rich in glyoogen). In the centre there is a focus of round cell infiltration in relation to degenerating liver cells. (H. and E. $\times$ 453.) 


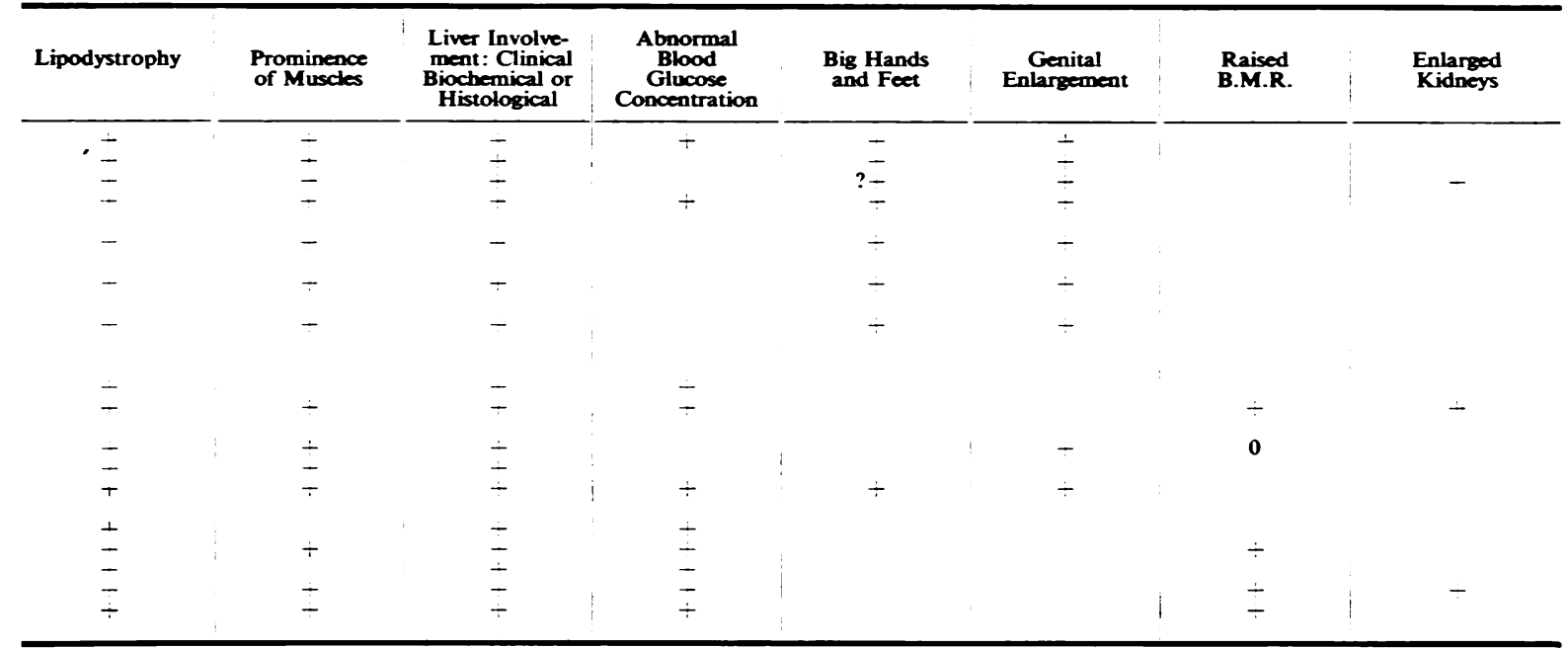

the neck, arms and upper trunk with the lower trunk and legs unaffected or even showing increased fat deposition (Murray, 1952).

Muscle Enbrgement. This was generalized and favoured no particular group. In some it was the most obvious feature at first glance, and imparted an athletic appearance. Muscle power appeared to accord with the enlargement.

Growth. The children tended to the 90th percentile or more for height and had enlargement

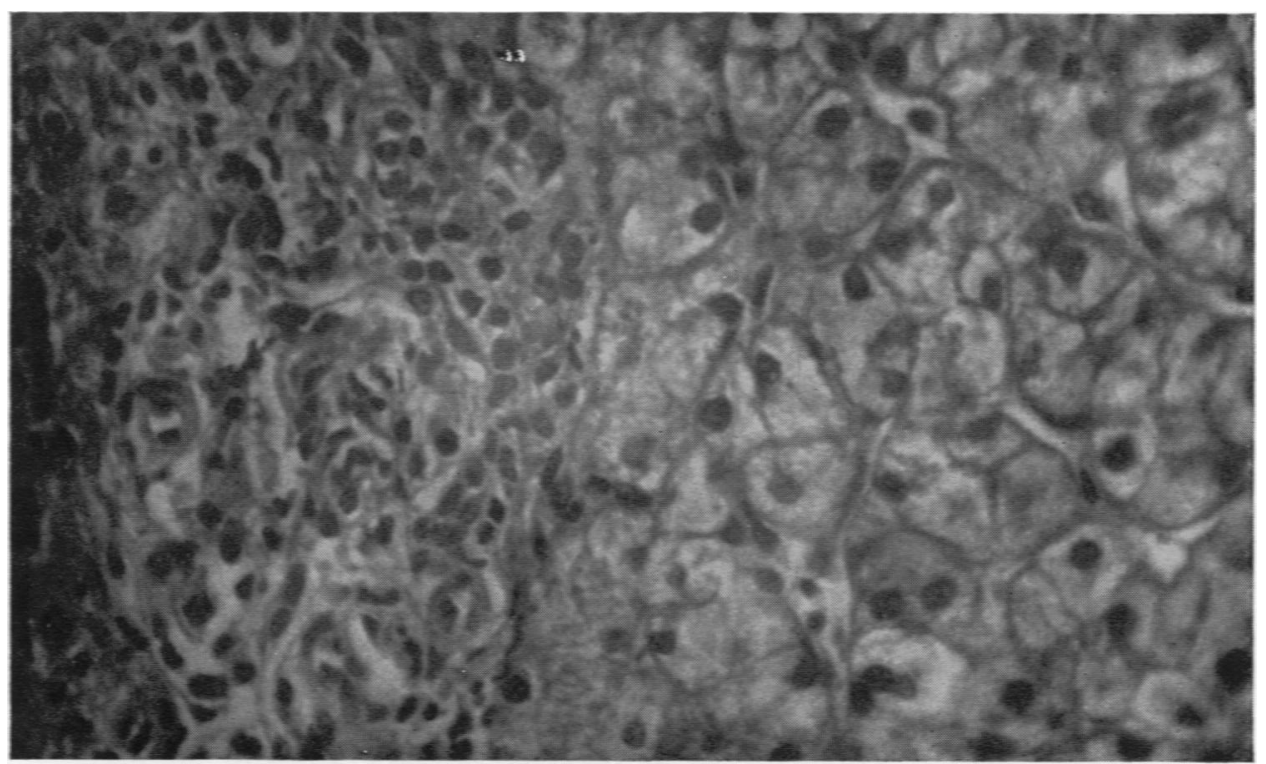

Fig. 5.-Photomicrograph showing section of liver with a portal tract (on the left) and periportal zone of liver lobule (on right). Round cell infiltration of the portal tract, and infiltration by these cells of the peripheral zone of liver lobule in relation to degenerating liver cells is shown. The liver cells on the right are rich in glycogen (confirmed by periodic acid-Schifi reaction and diastase response). (H. and $E$. $\times 453$.) 
of the hands and feet. Growth was unaffected in adults.

Derangements of Blood Sugar. A consistent pattern was not seen, but generally speaking hypoglycaemia was present in the young and hyperglycaemia in older subjects. The hyperglycaemia varied in degree from a raised glucose tolerance curve to severe diabetes which was insulin resistant. Ketosis was noticeably absent. Hyperplasia of the islets of Langerhans with an increased concentration of insulin in the pancreas was found in two infants (Donohue and Uchida, 1954) and there was increased plasma insulin activity in two other patients (Seip, 1959; Schwartz et al., 1960).

Genitalia. Enlargement of the clitoris and of the penis was present in the younger patients without evidence of increased secretion of adrenal androgens or of pituitary gonadotropin. Genital differentiation was otherwise normal in the females and no other virilizing features were present. This most unusual genital effect was not evident in the adults. Enlargement of the ovaries with follicular cyst formation was also present. No information is available regarding testicular histology.

Liver. Hepatomegaly was present and the empirical tests of liver function abnormal. Microscopic examination of the liver showed progression from patchy areas of swollen fused liver cells with mild fatty infiltration and heavy deposition of glycogen to irregular fibrosis and eventual cirrhosis. This appeared to be the cause of death in two patients.

Kidneys. Information regarding renal size is only available in four patients of the series (Lawrence, 1946; Corner, 1952; Donohue and Uchida, 1954), and in all there was enlargement with no histologically obvious cause.

Basal Metabolic Rate. The B.M.R. was estimated in six patients, three of them children, and found elevated in four. The raised B.M.R. was not due to thyroid overactivity. There appeared to be some correlation between the severity of the syndrome and the B.M.R. level.

Serum Lipids. Hyperlipaemia was commonly present and fractionation suggested the increase was of the neutral fraction.

Hirsuties and Pigmentation. Generalized slight pigmentation and fine hirsuties was apparent in a number of the patients. Curliness of scalp hair was also mentioned.
It has been suggested that the primary defect causing this syndrome is one involving storage of fat (Lawrence, 1946; Schwartz et al., 1960). However, in Lawrence's patient (Lawrence, 1946) the diabetes preceded the lipodystrophy and, moreover, it is difficult to understand how this defect could give rise to the other features. Again in partial lipodystrophy total fat stores are little altered, yet the other features are to be found (Murray, 1952).

The association of tallness, hirsuties, big hands and feet, mobilization of fat, increase of muscle mass, ovarian and genital enlargement and abnormal blood glucose concentrations strongly suggests a hormonal basis. However, no recognized hormone in man is known to produce this syndrome, although the major features, increased growth, increase in muscle mass, mobilization of depot fat and hypoglycaemia succeeded by hyperglycaemia have been induced by administration of 'growth hormone' pituitary extracts to animals (Astwood, 1955). In man an excess of growth hormone should produce gigantism in the child and acromegaly in the adult. Are there then two different growth hormones, the one causing acromegaly and the other the effects noted by physiologists and resembling the features present in the syndrome?

It is tentatively suggested, therefore, that the $8 \stackrel{\circ}{\mathscr{S}}$ syndrome results from oversecretion of a hormone having many of the effects attributed to 'growth hormone' extracts, but with mobilization of fat as its major function.

Kekwick and co-workers (Kekwick, 1960) have isolated from the urine of fasting subjects a substance resembling corticotrophin that mobilizes fat in mice. This substance has also been found in the urine of two non-fasting subjects with diffuse lipoatrophy. It may well be that elucidation of the relationship between this substance and pituitary growth hormone extracts will solve the aetiology of 'lipodystrophic muscular hypertrophy'.

Whilst it is postulated that the syndrome results from a primary excess of hormone secretion, it is tempting to suggest that secondary hypersecretion of the same hormone may be provoked by obesity and in turn be responsible for the non-ketotic insulin-resistant diabetes commonly present in such overweight subjects.

From the Table it will be seen that this condition was noted in some instances at birth, whilst in others it manifested later in life. The patients have therefore been tentatively allocated into congenital and acquired groups. Although the congenital group is small (nine patients) the story of consanguinity in four families (Hall et al., 1936; Berardinelli, 1954; Donohue and Uchida, 1954; Seip, 1959) two with 
two children affected (Donohue and Uchida, 1954; Seip, 1959) strongly suggests a genetic basis. The apparent absence of the syndrome in the parents and its presence in children of both sexes may indicate a homozygous recessive autosomal gene state.

Until a pathophysiological name becomes possible, 'lipodystrophic muscular hypertrophy' describes the two most obvious presenting features.

\section{Summary}

A girl of 2 years and 10 months with a number of unusual features including lipodystrophy, generalized muscular hypertrophy, hepatomegaly with biochemical and histological evidence of disordered function, enlargement of the hands, feet and clitoris, abdominal protuberance and a lowered concentration of glucose in the blood, is described.

There are reports in the literature of patients who appear to have the same syndrome in either 'congenital' or 'acquired' form.

It is suggested that the syndrome results from hormonal action, possibly from the excessive secretion of a specific pituitary hormone.

'Lipodystrophic muscular hypertrophy' is proposed as the name for the syndrome.

It is a pleasure to acknowledge the generous help given by Professor B. J. P. Becker with the histopathology and by Drs. W. M. Politzer, B. M. Bloomberg,
I. Bersohn and R. Sichel with the biochemical investigations.

I am grateful to Mr. W. Kark who performed the laparotomy and to Dr. L. Gotlieb and Mr. A. Shevitz for the photographs. The glucagon was donated by Eli Lilly Co.

\section{REFERENCES}

Astwood, E. B. (1955). 'Growth hormone and corticotropin.' In The Hormones: Physiology, Chemistry and Applications, ed. G. Pincus and K. V. Thimann, vol. III, p. 235. Academic Press,

New York. syndrome: Report of 2 cases. J. clin. Endocr., 14, 193.

Corner, B. D. (1952). Lipoatrophic diabetes. Arch. Dis. Childh., 27, 300 .

Donohue, W. L. and Uchida, I. (1954). Leprechaunism: A euphuism for a rare familial disorder. $J$. Pediat., 45, 505 .

Fontan, A., Verger, P., Couteau, J. M. and Pery, M. (1956). Hypertrophie musculaire généralisée à début précoce avec lipodystrophie faciale hépatomégalie et hypertrophie clitoridienne trophie faciale hépatomégalie et hypertrophie clitoride
chez une fille de 11 ans. Arch. franç. Pédiat., 13, 276.

Hall, B. E., Sunderman, F. W. and Gittings, J. C. (1936) Congenital muscular hypertrophy. A.M.A. Amer. J. Dis. Child., 52, 773 .

Hansen, A. E. and McQuarrie, I. (1940). Study of certain tissue lipids in generalized lipodystrophy: lipohistiodiaresis. Proc. Soc. exp. Biol. (N.Y.), 44, 611.

Kekwick, A. (1960). On adiposity. Brit. med. J., 2, 407.

Lawrence, R. D. (1946). Lipodystrophy and hepatomegaly with diabetes, lipaemia and other metabolic disturbances: a case throwing new light on the action of insulin. Lancet, 1, 724, 773.

Murray, I. (1952). Lipodystrophy. Brit. med. J., 2, 1236.

Schwartz, R., Schafer, I. A. and Renold, A. E. (1960). Generalized lipoatrophy, hepatic cirrhosis, disturbed carbohydrate metabolism and accelerated growth (lipoatrophic diabetes). Amer.J. Med. 28, 973.

Seip, M. (1959). Lipodystrophy and gigantism with associated endocrine manifestations: A new diencephalic syndrome? Acta paediat. (Uppsala), 48, 555.

Stuart, H. C. and Stevenson, S. S. (1959). Physical growth and development. In Nelson Textbook of Paediatrics, 7th ed. Saunders, Philadelphia and London.

Tizard, J. P. M. (1954). Generalized lipodystrophy. Infectious mononucleosis. Mild infantile hemiplegia. Proc. roy. Soc. Med., 47, 128

Ziegler, L. H. (1928). Lipodystrophies. Report of seven cases. 